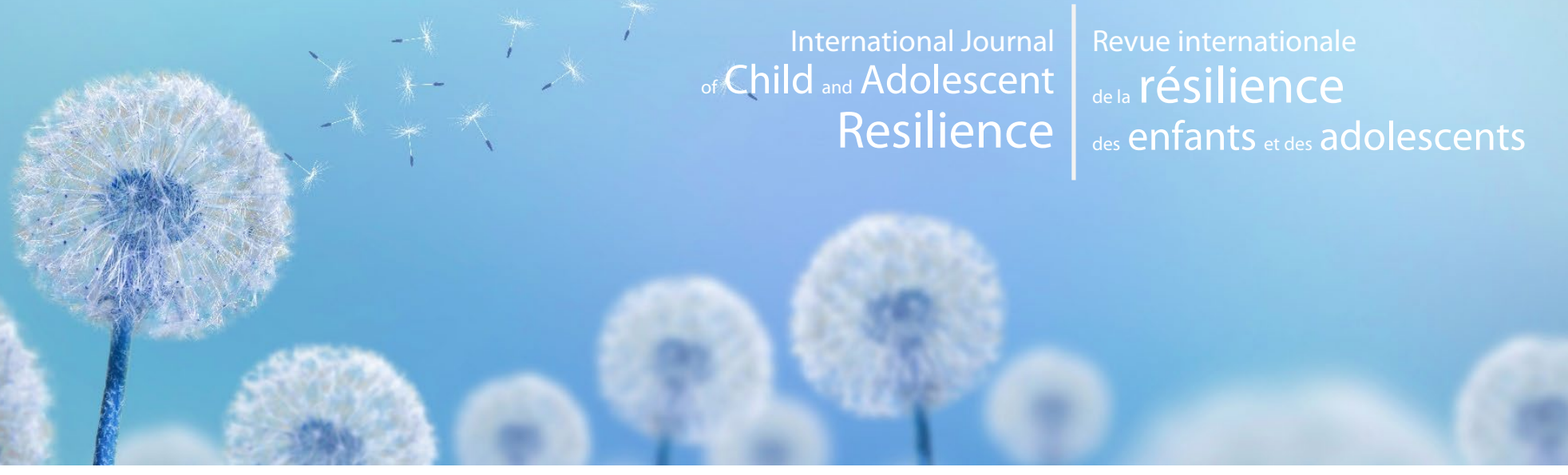

\title{
Mental health profiles of sexually abused youth: Comorbidity, resilience and complex PTSD
}

\section{Alexane ALIE-POIRIER', Martine HÉBERT ${ }^{2}$, Pierre MCDUFF', and Isabelle DAIGNEAULT ${ }^{1}$}

1 Department of Psychology, Université de Montréal

2 Department of Sexology, Université du Québec à Montréal

Corresponding Author: Isabelle Daigneault, Ph.D., Department of Psychology, Université de Montréal, P.O. box 6128, Downtown Station, Montréal, Québec, Canada H3C 3J7.

Email: isabelle.daigneault@umontreal.ca.

\section{Abstract}

Objectives: The current study's objectives were to 1) determine if sexually abused youth in child protective agencies (CPA) were given more psychiatric diagnoses and exhibited more comorbidity than youth from the general population, 2) examine the comorbidity profiles of sexually abused youth over 10 years of medical consultations and hospitalizations.

Method: Diagnoses of 882 youth with a substantiated sexual abuse report between 2001 and 2010 at a participating CPA were compared to those of 882 matched controls ( $n=1764$ ).

Results: Results of generalized linear mixed models showed that sexually abused youth presented higher rates of all diagnostic categories and were up to four times more likely to present comorbid diagnoses. Latent class analyses among abused youth revealed four different comorbidity profiles; two more severe groups named complex trauma (11\%) and dissociation (14\%); and two less severe groups named depression (10\%) and low or no comorbidity/resilience (65\%). Youth with more cumulative maltreatment and greater number of years of data following CSA report were more at risk of presenting a comorbidity profile, while females were more likely to present a depression profile. Profiles of youth in the highest comorbidity class were similar to what is defined as complex trauma or complex post-traumatic stress disorder.

Implications: Sexually abused youth's varied profiles warrant varied interventions. Integrated trauma informed interventions are needed to address the cumulative maltreatment experienced and the psychiatric comorbidity some youth exhibit.

Keywords: Child maltreatment, child sexual abuse, complex PTSD, comorbidity, resilience. 


\section{Introduction}

Although child sexual abuse (CSA) is a major worldwide problem with social, public health and safety as well as economic impacts, it remains difficult to comprehend its full extent for two reasons: 1) a lack of consensus on how to define CSA and 2) important differences in how prevalence data is collected (Goldman \& Padayachi, 2000; Johnson, 2008; Mathews \& Collin-Vézina, 2019). Hence, the current study broadly defines CSA as "any gesture of a sexual nature, with or without physical contact, committed by an individual without consent from the person, or, in some cases, particularly that of children, through emotional manipulation or coercion" (Gouvernement du Québec, 2016). International data from a substantial meta-analysis suggest that 18\% of women and $8 \%$ of men report having been sexually abused before the age of 18 (Stoltenborgh et al., 2011). When also self-reported, CSA prevalence is much higher (35.8-38\%) in children and adolescents within youth protection agencies (CPA) than in the general population (CollinVézina et al., 2011; Pauzé et al., 2000). Importantly, it has been documented that CSA is grossly underreported to authorities (Stoltenborgh et al., 2011).

Although research has documented the short- and long-term consequences of CSA within CPA populations (Bourgeois et al., 2018), gaps remain in our understanding of the clustering of comorbid mental health outcomes. Existing research has mainly used variable-centered analyses, which may not capture heterogeneity among these youth. In addition, previous research has mostly relied on self-report measures and cross-sectional or retrospective methods, which entail some biases and limit our understanding of how CSA consequences evolve over time (Belsky, 1993; Brewin et al., 1993; Brownell \& Jutte, 2013; O'Donnell et al., 2010a, 2010b; Stanley, 2003; Straus, 1998). To overcome some of these limitations, the current study will attempt to better understand the consequences of CSA using a personcentered approach and administrative longitudinal data.

\section{Consequences of child sexual abuse}

CSA increases the risk of psychiatric disorder by 2.5 folds (Fergusson et al., 2008). When assessed in childhood or adolescence, sexually abused youth tend to present a host of different mental problems, while about a third present no symptoms at all (for reviews see Finkelhor \& Hashima, 2001; Kendall-Tackett et al., 1993; Putnam, 2003; Tyler, 2002). Indeed, higher rates of internalizing (e.g. anxiety, depression) and externalizing problems (e.g. antisocial behaviour), suicidal ideation, substance use and other psychiatric diagnoses (Choi et al., 2017; Fergusson et al., 2008), such as posttraumatic stress disorder (PTSD) and dissociation or psychosis (Bourgeois et al., 2018), are linked to CSA. When assessed in young adulthood, very similar consequences are reported (for reviews see Hillberg et al., 2011; Maniglio, 2009).

Although CSA does not seem to lead to consequences that are specific or unique, PTSD remains the most studied (Kearney et al., 2010; Putnam, 2003) and is among the most common disorders observed in sexually abused children and adolescents (Choi et al., 2017; Kendall-Tackett et al., 1993). A fourth of sexually abused youth under CPA care present with PTSD (Collin-Vézina et al., 2011; Daigneault et al., 2003). Some studies have assessed various disorders comorbid with PTSD like depression and suicidality (Brosbe, 2014; Oquendo et al., 2003), but failed to use a personcentered approach. Moreover, in most studies, documented consequences are self-reported. Hence, there is much need to specifically study wider co-occurrence of disorders, or diagnostic comorbidity, as a consequence of CSA in order to reliably identify symptom constellation variations and similarities within sexually abused youth. Doing so will thus ensure the most adequate and precise interventions in response to specific psychiatric profiles.

\section{Symptom comorbidity}

Some sexually abused children and adolescents tend to present complex adaptation profiles (Collin-Vézina et al., 2011; Daigneault et al., 2004; Tremblay et al., 2000) that could better be understood using a conceptualization based on complex post-traumatic reactions (Cloitre et al., 2009, 2013; Cook et al., 2005; Ford, 2011; Hyland, Shevlin, Elklit, et al., 2016; van der Kolk, 2017). Adolescents exposed to CSA present more comorbid mental health problems like PTSD, depression and suicidality than other youth who have not been sexually abused (Kilpatrick et al., 2003; Martin et al., 2004), even within those receiving psychiatric care who tend to present an array of complex psychological and behavioural disorders (Brand et al., 1996; Ford et al., 2011; Naar-King et al., 2002; Silverman et al., 1996). Among sexually abused youth with PTSD symptoms, although specific comorbidities have been documented (Ackerman et al., 1998; Brosbe, 2014), such as internalizing disorders (Brady \& Caraway, 2002; Connor et al., 2004), and externalizing disorders (McLeer et al., 1998), studies tend to measure only two or three different diagnoses at a time (Kaplow et al., 2008).

Hence, sexually abused youth that present an array of different problems, usually corresponding to more than one different diagnostic category, can be attributed multiple diagnoses. The concept of complex trauma, 
developmental trauma disorder, or complex PTSD (CPTSD; Cloitre et al., 2013; Hyland, Shevlin, McNally, et al., 2016) might be useful in explaining why some youth present various symptoms that can initially seem distinct, but better understood as a complex consequence of CSA. Although currently not retained in the DSM's fifth edition (American Psychiatric Association [APA], 2013) the concept of CPTSD has been studied and proposed to be conceptually distinct from PTSD (Cloitre et al., 2013; Hyland, Shevlin, McNally, et al., 2016) and clinically valid (Hyland, Shevlin, Elklit, et al., 2016). Currently, the diagnosis of PTSD includes four groups of symptoms: re-experiencing, avoidance, negative cognitions and mood, and arousal (World Health Organization [WHO], 2020). The proposed symptom profile of CPTSD includes all PTSD symptoms, plus an additional three categories that identify disturbances in self-organization, which may result from sustained and repeated interpersonal trauma. These categories are: (a) affective dysregulation, (b) negative self-concept, and (c) disturbed relationships (Ford \& Courtois, 2014; WHO, 2020). Various functional domains can be severely impacted in the case of complex trauma, such as affect and behavior dysregulation, consciousness and cognition disturbances, alterations in attribution and schema, and interpersonal impairment (D'Andrea et al., 2012). This can result in youth being given multiple comorbid diagnoses, corresponding to current psychiatric nosology, but perhaps inaccurate to best describe many victimized children, thus providing them with inappropriate treatment.

The use of person-centered analytic techniques, such as latent class analysis, is gaining interest in determining whether there are distinct mutually exclusive groups of individuals based on reported experiences of maltreatment (Rivera et al., 2018), reported psychiatric diagnoses in CSA victims (Brodbeck et al., 2018) or trauma symptoms (Gallitto et al., 2017). Indeed, some studies have tried to better understand how CSA victims can be distinguished among themselves and compared to non-sexually abused individuals. Although there is vast heterogeneity, general findings suggest three to four distinct profiles with an incremental range in the severity of consequences between groups (i.e. none or very few, some or moderate, multiple and severe), as well as a dose-response association between the severity of CSA or maltreatment (all types including CSA) and symptoms (Brodbeck et al., 2018; Hébert et al., 2006; Shin et al., 2010). Most of these studies used cross-sectional designs and small samples, which limits the ability to determine the timing of events (diagnoses and CSA) and undermines statistical power. The use of prospective data, in the case of the current study, is extremely valuable.

\section{Maltreatment co-occurrence}

The growing research focusing on the effects of interpersonal trauma within child welfare involved youth (Daigneault et al., 2003; Tanaka et al., 2011; Wekerle et al., 2017) shows that adolescents involved in CPA have higher rates of serious mental health disorders compared with the general adolescent population. Furthermore, it has been found that among youth under CPA care, more than half had experienced more than four types of victimization in the past year (Cyr et al., 2013). Between 22\% and 90\% of maltreated youth or those involved in child welfare (Lau et al., 2005; Tourigny et al., 2008; Turner et al., 2010) and up to 69\% in the general population report polyvictimization or cumulative traumatic experiences (Felitti et al., 1998; Finkelhor et al., 2009, 2015; Ford et al., 2010). Such high prevalence in the general population might be explained by the inclusion of non-traumatic adversity in some studies (e.g. parental substance abuse, serious illness, parental conflict) (Finkelhor et al., 2009, 2015). Although CSA is reported less frequently than other types of maltreatment (Brown et al., 2019; Stoltenborgh et al., 2011), it rarely occurs in isolation (Vachon et al., 2015). It is now documented that there is a dose-response effect when considering the consequences of cumulative maltreatment, where a higher number of distinct forms of maltreatment is associated with a greater number of symptoms of current distress (Finkelhor et al., 2009; Steine et al., 2017). Indeed, CSA has been associated with a threefold greater weight than all forms of maltreatment and victimization taken together in predicting short- and long-term psychological consequences (Finkelhor et al., 2009). It is thus important to consider both the cumulative and specific effects of CSA.

\section{Specific aims and hypotheses}

The first aim of this study is to document the prevalence of diagnostic comorbidity of mental health disorders, using data from administrative databases of a universal public health insurance agency for children and adolescents up to 13 years following a substantiated sexual abuse report, compared with that of a matched group from the general population (children without substantiated CSA). The second aim is to document the diagnostic comorbidity profiles of these youth using a person-centered analytic approach and to underline the characteristics that distinguish them such as gender, age at CSA report as well as cumulative maltreatment in addition to CSA. The current study will palliate limits of previous studies with a matched cohort study design using longitudinal data from a universal public health insurance administrative database, while controlling for mental health problems preceding the CSA report 
substantiation. Importantly, the current administrative data offers reliable and comparable diagnostic information for the substantiated CSA group as well as the general population group without CSA reports (matched), which palliates biases of prior self-report designs (Brewin et al., 1993; O'Donnell et al., 2010b; Straus, 1998).

Current literature allows us to generate the following hypotheses: the group of sexually abused youth will present 1) more mental health disorders in all diagnostic categories and 2) higher rates of comorbid mental health disorders than the general population. Furthermore, we expect to observe at least three distinct groups within sexually abused youth (Hypothesis 3): youth without diagnoses, youth with only one diagnosis, and youth with two or more different diagnoses. Groups of sexually abused youth with the highest diagnostic comorbidity are also expected to have the highest rates of cumulative maltreatment (thus a greater chance to present as complex trauma) when compared with abused youth presenting no diagnostic comorbidity or no mental health disorder diagnoses (Hypothesis 4).

\section{Materials and Method}

\section{Data and sample}

The current study selected all children who had a substantiated report of sexual abuse at a large urban CPA in Canada between January 1, 2001, and December 31, 2010. They formed the sexually abused group ( $n=955)$. Personal information from the administrative databases of the universal public health insurance agency was matched to those from the CPA for 882 (92\%) of the 955 children with substantiated sexual abuse by using participants' health insurance number, or their surname, name, complete address and date of birth. The Canadian public health system covers all Canadian citizens, those currently residing as well as authorized foreign nationals, with their accompanying spouses and children. It is likely that misspelling of administrative data (i.e. names, surnames and addresses) could explain unmatched cases. Recent results using this same database indicated that excluded unmatched sexually abused cases received fewer services than matched sexually abused cases, suggesting less severe diagnostic profiles (Daigneault, Vézina-Gagnon, et al., 2017).

To form the control group, each of the sexually abused participants $(n=882)$ was paired with another youth from the administrative database of the province's universal public health insurance. The criteria used were birth month and year, gender attributed at birth, geographical area from which sexually abused participants were selected, and an indicator of socio-economic level (i.e., eligibility to the province's prescription drug insurance plan). Bearing in mind that sexual abuse is grossly underreported to authorities (Afifi et al., 2015), even if no substantiated sexual abuse was reported during the 10-year recruitment, there is no way of knowing with certainty if some participants were exposed to CSA within the control group, meaning that some CSA most likely has occurred unreported. Furthermore, if reports were made, they could have been found unsubstantiated or made to another CPA if children moved from one geographic area to another. In both cases, this information would not have been available in the current data.

The final sample was composed of 882 children and adolescents for whom a sexual abuse report was substantiated within the CPA and 882 matched individuals from the general population (no reported CSA). Each of these two groups is composed of 661 girls (75\%) and 221 boys (25\%). This represents a total sample of 1764 . The average age of the participants at the time of entry in the study (date of the substantiated report of sexual abuse to (PA) was 11.07, and previous analyses showed that boys were 1.4 years younger than girls at the time of the first CSA report (Daigneault, Vézina-Gagnon, et al., 2017).

In the sexually abused group, the number of different substantiated reports varied from 1 (40\% of abused youth) to $4(8 \%)(M=3.12, S D=2.87)$. This means that although CSA was the first substantiated report to CPA for most participants (88\%), other maltreatment reports were also substantiated, whether prior to, after, or co-occurring with the sexual abuse, such as negligence (31\%), physical abuse (10\%), behaviour problems (8\%) and abandonment (2\%). At the end of the study, the principal reason for CPA involvement remained sexual abuse for most youth (60\%). For some youth, though, negligence (28\%), maltreatment (5\%), behaviour problems (5\%) and abandonment (1\%) became the principal reason for receiving CPA services. 


\section{Measures}

Sexual abuse. In the current study, sexual abuse was defined as "any gesture of a sexual nature, with or without physical contact, committed by an individual without consent from the person, or, in some cases, particularly that of children, through emotional manipulation or coercion" (Gouvernement du Québec, 2016). When a sexual abuse report is substantiated, it satisfies a series of criteria. It must first be retained for evaluation. Then, a social worker must assess if there is sufficient evidence to substantiate the CSA report and the case is either found to be 1) substantiated (sufficient evidence that CSA occurred), 2) suspected (suspicion of CSA but insufficient evidence to substantiate the allegations), or 3) unsubstantiated (enough evidence to refute CSA) (Gouvernement du Québec, 2008). The present study selected all children who had at least one substantiated report of sexual abuse between 2001 and 2010 (recruitment period) at the participating CPA to form the group of sexually abused youth. To avoid duplication of reports and participants, the first substantiated report of sexual abuse was considered for each participant and determined his or her time of entry into the study. All subsequent substantiated sexual abuse reports were calculated as additional to the first report. The control group, or matched group, included youth who resided in the same geographical area served by the participating CPA and most importantly, who did not have a substantiated report of sexual abuse between 2001 and 2010 at that same CPA (see procedures above for more detail on control group selection).

Maltreatment co-occurrence. For each sexually abused youth, data from the CPA was provided for all other substantiated reports on file, dating back to the first substantiated report and up until the end of the study December 31,2013 , which provides information on cumulative substantiated maltreatment. A report is substantiated when the security or development of a child is judged to be compromised - when "the child is abandoned, neglected, subjected to psychological ill-treatment or sexual or physical abuse, and unique to Quebec, if the child has serious behavioural disturbances" (Gouvernement du Québec, 2016). Hence, for each sexually abused youth, a global score of cumulative maltreatment was obtained by adding all substantiated maltreatment reports, resulting in a continuous variable ranging from 0 to 20. This information was unavailable for the control group.

Mental health. All diagnoses of mental and behavioural disorders related to medical services received and hospitalizations occurring between January 1, 1996, and March 31, 2013, were documented from the universal public health insurance agency and the Ministry of Health's administrative databases. The codes in these databases refer to the 10th version of the International Classification of Diseases (ICD; WHO, 2008), as it is the medical reference in the public health system. As described in Table 1, the following categories were used in the current study: 1) disorders due to psychoactive substance use (ICD code F10-F19), 2) schizophrenia, schizotypal and delusional disorders (F20-F29), 3) disorders of the adult personality and behaviour (F60-F69), 4) disorders of psychological development (F80-F89), 5) unspecified mental disorder (F99), 6) depressive episodes and disorders (F32-F39), 7) bipolar disorders and manic episodes (F30-F31), 8) reactions to severe stress and adjustment disorders (i.e. post-traumatic stress disorder, acute stress reaction and adjustment disorder; F43), 9) anxiety disorders and phobias (F40-F42), 10) somatoform and dissociative disorders (F44-F48), 11) eating disorders (F50), 12) behavioural syndromes associated with physiological disturbances (F51-F59), 13) hyperkinetic disorders and 14) conduct, emotion or social functioning disorders with childhood onset (F91-F99). For each of the 14 diagnostic categories, a dichotomous score was computed documenting whether each participant had at least one medical consultation or hospitalization for a diagnosis in that category after the first substantiated CSA report. This timeline was paired in the matched control group. A diagnostic comorbidity score was then calculated and varies from 0 to 14, with a higher score indicating greater diagnostic comorbidity in distinct diagnostic categories following the CSA report.

Control variables. A deprivation index (material and social) (Pampalon et al., 2010) based on postal code, which indicates the socio-economic level of the geographical area at the time of the first substantiated report of sexual abuse, was used and controlled for in all analyses within both groups. For participants in the matched control group, the index was calculated at the time of the first CSA report of the abused child they were matched with. The total number of medical services (consultations/hospitalizations) received for mental health issues between January 1, 1996, and the first substantiated CSA report, using the same diagnoses described previously, were also controlled for. This timeline was paired in the matched control group to create the control variable. Furthermore, using the same timeline in both groups, consultations and hospitalizations for mental retardation/intellectual disability diagnosed before the first substantiated report of abuse were controlled for, since it is a known risk factor of sexual abuse and mental health disorders (Euser et al., 2015). Finally, the number of years for which data could be collected for each participant, meaning number of years between first CSA report and end of the study, was also controlled for in subsample analyses 
of sexually abused youth. All analyses were conducted with the SPSS 26 program (IBM Corp, Armonk, New York), with a $p<.05$ significance level.

Table 1. ICD-10 broad and specific diagnostic categories included in the study

\begin{tabular}{|c|c|c|}
\hline Variables & $\begin{array}{l}\text { Broader diagnostic categories } \\
\text { (corresponding numbers) }\end{array}$ & Specific diagnostic categories (corresponding numbers) \\
\hline Substance use & $\begin{array}{l}\text { Mental and behavioural disorders due to } \\
\text { psychoactive substance use (F10-F19) }\end{array}$ & $\begin{array}{l}\text { Alcohol (F10), opioids (F11), cannabinoids (F12, sedatives (F13), cocaine (F14), } \\
\text { other stimulants (F15), hallucinogens (F16), tobacco (F17), volatile solvents } \\
\text { (F18), other (F19) }\end{array}$ \\
\hline Schizophrenia & $\begin{array}{l}\text { Schizophrenia, schizotypal and } \\
\text { delusional disorders (F20-F29) }\end{array}$ & $\begin{array}{l}\text { Schizophrenia (F20), schizotypal (F21), persistent delusional (F22), acute and } \\
\text { transient psychotic (F23), induced delusional (F24), schizoaffective (F25), other } \\
\text { (F28), unspecified (F29) }\end{array}$ \\
\hline Personality & $\begin{array}{l}\text { Disorders of adult personality and } \\
\text { behaviour (F60-F69) }\end{array}$ & $\begin{array}{l}\text { Specific personality (F60), mixed (F61), enduring personality changes (F62), } \\
\text { habit and impulse (F63), gender identity (F64), sexual preference (F65), sexual } \\
\text { development (F66), other (F68), unspecified (F69) }\end{array}$ \\
\hline Development & $\begin{array}{l}\text { Disorders of psychological development } \\
\text { (F80-F89) }\end{array}$ & $\begin{array}{l}\text { Development of language (F80), scholastic skills (F81), motor function (F82), } \\
\text { mixed (F83), pervasive (F84), other (F88), unspecified (F89) }\end{array}$ \\
\hline Unspecified & Unspecified mental disorder (F99) & Mental disorder, not otherwise specified (F99) \\
\hline Manic/bipolar & & Manic episode (F30), bipolar affective (F31) \\
\hline Depression & Mood [affective] disorders (F30-F39) & $\begin{array}{l}\text { Depressive episodes (F32), recurrent depression (F33), persistent mood (F34), } \\
\text { other (F38), unspecified (F39) }\end{array}$ \\
\hline Anxiety/phobias & & Phobic anxiety (F40), other (F41), obsessive compulsive (F42) \\
\hline PTSD & Neurotic, stress-related and somatoform & Reaction to severe stress and adjustment (F43) \\
\hline $\begin{array}{l}\text { Dissociation and } \\
\text { somatoform }\end{array}$ & disorders (F40-F49) & Dissociative (F44), somatoform (F45), other (F48) \\
\hline Eating disorders & Behavioural syndromes associated with & Eating (F50) \\
\hline $\begin{array}{l}\text { Physiological } \\
\text { impact }\end{array}$ & $\begin{array}{l}\text { physiological disturbances and physical } \\
\text { factors (F50-F59) }\end{array}$ & $\begin{array}{l}\text { Sleep (F51), sexual dysfunction (F52), psychological factors associated with } \\
\text { disease (F54), abuse non-dependence substance (F55), unspecified (F59) }\end{array}$ \\
\hline Hyperkinetic & Behavioural and emotional disorders & Hyperkinetic disorders (F90) \\
\hline $\begin{array}{l}\text { Conduct and } \\
\text { social }\end{array}$ & $\begin{array}{l}\text { with onset usually occurring in } \\
\text { childhood and adolescence (F90-F98) }\end{array}$ & $\begin{array}{l}\text { Conduct (F91), mixed of conduct and emotion (F92), emotional (F93), social } \\
\text { functioning (F94), tic (F95), other (98) }\end{array}$ \\
\hline
\end{tabular}

\section{Results}

\section{Objective 1 (descriptive analyses)}

Descriptive results presented in Table 2 show the percentage of participants who received services related to diagnoses in the 14 categories described previously. The highest rates of diagnoses for both CSA and control groups fell within the categories of neurotic disorders (specifically anxiety and phobias), conduct and social disorders with onset in childhood and dissociation and somatoform disorders.

\section{Objective 1: Hypothesis 1}

To determine whether sexual abuse was associated with higher comorbidity for mental health disorders, a negative binomial regression was used. This type of analysis is the most accurate to account for the matched-cohort design, whereby the identical values upon which the participants have been matched are eliminated from further consideration (Niven et al., 2012). Results showed that, controlling for material and social deprivation, intellectual disability and mental health prior to the CSA report, sexually abused youth were 3.6 times more at risk ( $95 \%$ confidence interval $[\mathrm{Cl}] 2.13-6.01$ ) of presenting with a mental health disorder in at least one diagnostic category than matched youth from the general population $(f(1,1688)=15.41, p<.001)$. One quarter of sexually abused youth presented very high diagnostic comorbidity prevalence (22\%; presence of at least one diagnosis in four or more different categories), compared to a minority in the general population (6\%). 


\section{Objective 1: Hypothesis 2}

Descriptive results in Table 2 indicate that diagnostic comorbidity is much higher for sexually abused youth than for controls. Paired t-test results reveal that, on average, abused youth have significantly higher total diagnostic comorbidity scores $(M=1.96, S D=2.47)$ than their matched-control peers $(M=0.67, S D=1.31$; paired $t(881)=14.11$, $p<.001)$.

Table 2. Diagnostic prevalence within each category and for comorbid category occurrences ( $n=1764)$

\begin{tabular}{llrl}
\hline & & CSA \\
& & $\begin{array}{c}\text { Control } \\
(n=882)\end{array}$ & $\% 82)$ \\
& & $\%$ & 6.80 \\
F10 - F19 & Disorders due to psychoactive substance use & 1.13 & 1.93 \\
F20 - F29 & Schizophrenia and delusion disorders & 0.28 & 5.95 \\
F60 - F69 & Disorders of the adult personality and behavior & 0.68 & 6.35 \\
F80 - F89 & Disorders of psychological development & 2.10 & 6.63 \\
F99 & Unspecified mental disorder & 1.36 & 8.11 \\
F32 - F39 & Depression & 2.44 & 1.02 \\
F30 - F31 & Bipolar and manic disorders & 0.17 & 15.59 \\
F40 - F42 & Anxiety and phobias & 6.24 & 6.07 \\
F43 & Reactions to severe stress and adjustment disorders & 1.53 & 13.15 \\
F44-F48 & Dissociation and somatoform disorders & 4.88 & 0.28 \\
F50 & Eating disorders & 0.40 & 7.09 \\
F51 - F59 & Behavioral syndromes associated with physiological disturbances/physical factors & 2.32 & 11.17 \\
F90 & Kinetic disorders with onset in childhood/adolescence & 3.80 & 13.49 \\
F91 - F98 & Conduct and social disorders with onset in childhood/adolescence & 5.61 & 37.96 \\
0 diagnosis & 71.32 & 19.89 \\
1 diagnosis & 13.41 & 20.26 \\
2-3 diagnoses & 9.72 & 22.89 \\
4+ diagnoses
\end{tabular}

\section{Objective 2: Hypothesis 3}

To document the diagnostic comorbidity profiles of sexually abused youth, a series of latent class analyses (LCA) were used. This analysis was solely performed on data from the sexually abused group, because results showed diagnostic comorbidity levels were not comparable between groups and there were too few participants with four or more diagnoses in the general population group. Additionally, variables on which to compare the profiles, such as cumulative maltreatment, were only available for the sexually abused youth. LCA postulates that the unobserved homogenous subgroups in a heterogeneous population can be identified using identifiable variables, in this case mental health diagnoses (Collins \& Lanza, 2010). This means the LCA estimates the probability of a presence vs. absence of diagnoses according to latent class membership. The LCA also estimates how many participants are expected to belong to each latent class. Using SPSS (Version 26) and a LCA model using R (R Core Team, 2017), LCA were based on the 14 dichotomous diagnostic category variables. To select the preferred model, we relied on the lowest value of the Akaike information criteria (AIC) and the lowest value of the sample-size adjusted Bayesian information criterion (BIC). Indicators like AIC and BIC have been shown to consistently demonstrate better fit of classes (Nylund et al., 2007). The general practice of LCA is to test a sequence of models, increasing the number of classes, and to choose the best fitting model according to adjustment indicators. As presented in Table 3, adjustment indicators were compared for solutions between two and five classes, and a four-class solution was retained.

Results illustrated in Figure 1 describe the probabilities profiles for each of the four classes. A first class (65.3\%), named "no diagnostic comorbidity," represented all sexually abused youth with no diagnoses and some with a very low probability of presenting one or two diagnoses. When compared to other classes, this first class is the largest and the one with least diagnostic comorbidity. A second class (14\%) regroups abused youth with the highest probability of presenting at least one diagnosis from the dissociative disorders category in addition to conduct and social or anxiety disorder categories. This class was named "dissociation." A third class (10.6\% of abused participants) named "complex trauma" emerged, grouping participants who all (100\%) had a diagnosis of conduct or social disorder as well as a high probability of presenting diagnoses in multiple distinct categories. More than half of abused youth in that class presented diagnoses in the following categories: personality, depression, PTSD, unspecified, anxiety and phobias, 
somatoform and dissociation, as well as disorders with a physiological impact. Indeed, all participants had at least one diagnosis in four or more different categories, meaning all participants presented highly comorbid profiles of mental health. A final and fourth class (10.1\%) named "depression and physiological impact" grouped participants presenting mostly depressive disorders, physiological impact disorders and anxiety disorders.

Table 3. Model fit information for competing latent class models

\begin{tabular}{ccrr}
\hline No classes & Likelihood ratio & \multicolumn{1}{c}{ AIC } & \multicolumn{1}{c}{ BIC } \\
\hline 2 & $-5,725.00$ & $11,507.99$ & $11,666.78$ \\
3 & $-5,554.86$ & $11,197.71$ & $11,438.63$ \\
4 & $-3,550.07$ & $7,218.13$ & $7,500.84$ \\
5 & $-5,346.00$ & $10,840.00$ & $11,245.17$ \\
\hline
\end{tabular}

Figure 1. Probabilities of diagnosis and comorbidity by latent class.

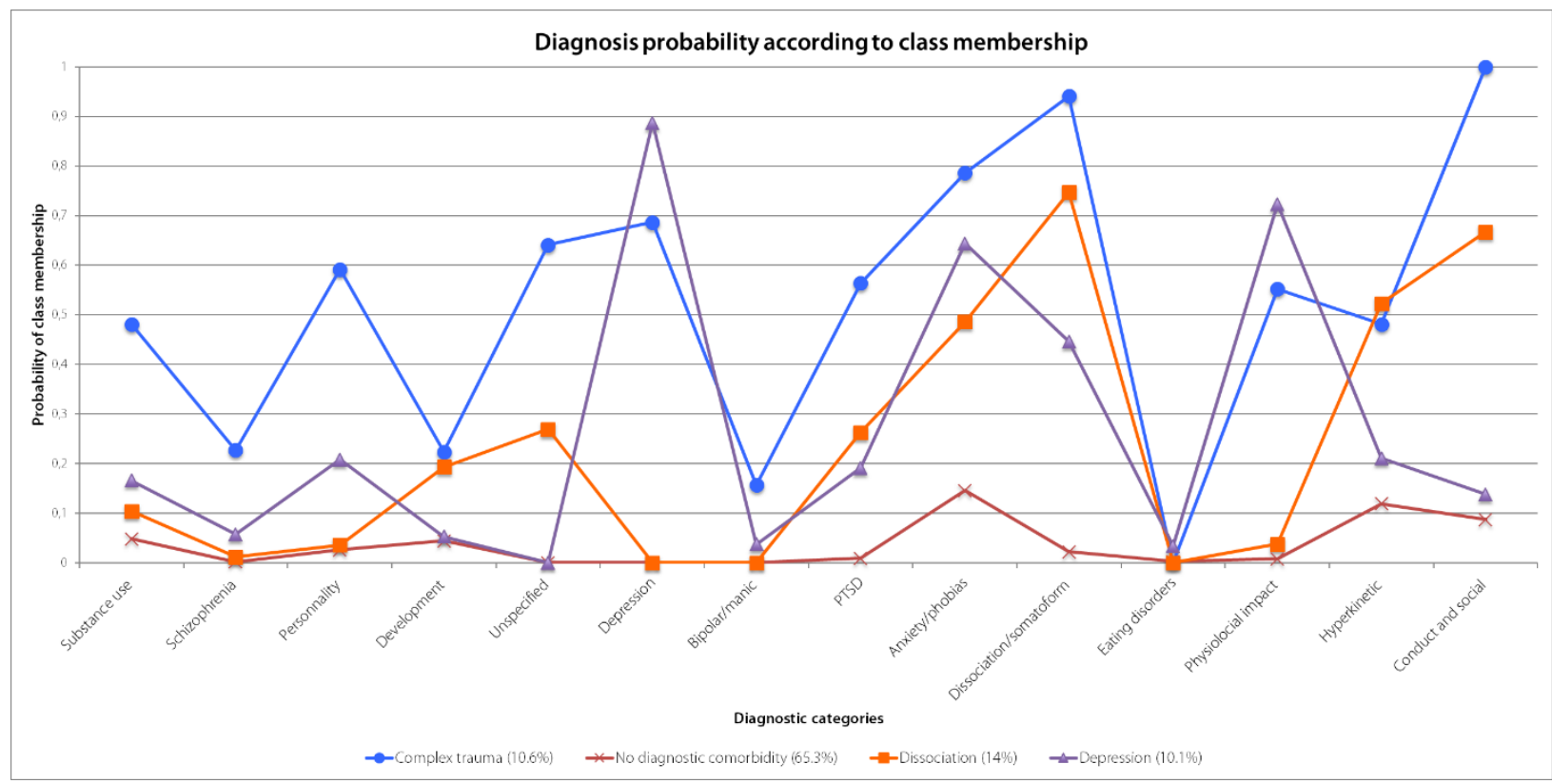

Note. Red line (x): no diagnostic comorbidity/resilient class, orange line (squares): dissociation class, blue line (circles): complex trauma class, purple line (triangles): depression/physiological impact class.

\section{Objective 2: Hypothesis 4}

To determine if gender, number of years following first reported CSA and number of substantiated types of reported maltreatment were associated with the four profiles found in the latent class analysis, a multinomial regression was used. The regression was weighted according to the probabilities of belonging to each latent class identified. Model fit was good $\left(X^{2}=48.85(9), p<.001\right)$ and results showed that gender was only a predictor of membership in the depression class, with females being almost twice as likely as males to be included (relative risk $=1.94$ ([CI] 1.06-3.58), $S E=.31, p=.03$ ). Cumulative maltreatment also predicted membership in the depression class (relative risk $=1.09[\mathrm{Cl}]$ 1.01-1.18), $S E=.04, p=.045)$. Both the dissociation and the complex trauma class membership could be predicted by a higher number of years following CSA (relative risk $=1.08$ ([Cl] 1.00-1.17), SE $=.04, p=.047$; relative risk $=1.21$ ([Cl] 1.10-1.32), $S E=.05, p=.008$, respectively) and a higher number of cumulative maltreatment (relative risk $=1.11$ ([Cl] 1.04-1.19), $S E=.03, p<.001$; relative risk $=1.16$ ([Cl] 1.08-1.24), $S E=.03, p<.001$, respectively). This means that abused youth were more likely to belong either to the complex trauma class or to the dissociation class with each additional year of follow-up data available and with each additional cumulative substantiated maltreatment report to CPA, which was not the case for the no diagnostic comorbidity class. Percentages of diagnostic comorbidity, cumulative maltreatment and gender by class membership are presented in Table 4. 
Table 4. Maltreatment co-occurrence, comorbidity and gender according to class $(n=882)$

\begin{tabular}{|c|c|c|c|c|c|c|c|c|c|c|}
\hline \multirow[b]{2}{*}{ Class } & \multicolumn{4}{|c|}{ \% Maltreatment types } & \multicolumn{4}{|c|}{$\%$ Comorbid diagnoses } & \multicolumn{2}{|c|}{$\%$ Gender } \\
\hline & 0 & 1 & 2 & $>3$ & 0 & 1 & 2 or 3 & $>3$ & Females & Males \\
\hline Low comorbidity & 46 & 13 & 10 & 26 & 60 & 28 & 12 & - & 75 & 25 \\
\hline Dissociation & 31 & 20 & 14 & 36 & - & 53 & 47 & - & 71 & 29 \\
\hline Complex trauma & 23 & 17 & 18 & 46 & - & - & - & 100 & 73 & 27 \\
\hline Depression & 41 & 10 & 8 & 41 & - & 43 & 57 & - & 85 & 15 \\
\hline
\end{tabular}

\section{Discussion and conclusion}

The current study had two objectives. First, to document the prevalence of comorbid mental health disorders in the administrative databases of the universal public health insurance agency of children and adolescents up to 13 years following a substantiated sexual abuse report. Second, to identify trauma-related symptom profiles of these childwelfare-involved children and adolescents. Results have revealed that abused youth have a greater risk of presenting mental health disorder diagnoses (Hypothesis 1) and higher comorbidity (Hypothesis 2). They also revealed four distinct classes of comorbidity in the abused group (Hypothesis 3), which were subsequently associated with gender, longer follow-up periods and cumulative substantiated reports of maltreatment (Hypothesis 4).

As expected, sexually abused youth presented significantly higher rates of all mental health disorders categories put together and higher comorbidity than youth in the general population. Youth exposed to CSA were almost four times more likely to receive at least one mental health diagnosis from their physician than their general population peers. This is coherent with other study results (Collin-Vézina et al., 2011; Kessler et al., 2010; Stoltenborgh et al., 2011). Results also showed that the highest prevalence in specific diagnostic categories for the sexually abused group was for anxiety and phobias, dissociation and somatoform disorders, and conduct disorders. This is coherent with past study results that have shown that CSA victims tend to present more childhood mental disorders, anxiety and acute stress disorders, as well as conduct disorders (Spataro et al., 2004). Almost a quarter of sexually abused youth presented at least one diagnosis in more than four different diagnostic categories, compared to a minority of youth in the general population. Indeed, the varied and possibly highly detrimental impact of CSA on mental health has been shown previously (Fergusson et al., 2008) and was also found in the current study. We further investigated comorbidity profiles within sexually abused youth, which have shown to range from no comorbidity (0-1 diagnosis) to very high comorbidity (4-13 distinct diagnostic categories).

Results showing different mental diagnostic comorbidity profiles of sexually abused youth revealed that great heterogeneity was present. Specifically, we uncovered four different profiles (classes). We expected to find at least three different profiles, so results are coherent with our hypotheses in terms of the number of profiles but also the characteristics that define these profiles. Indeed, we predicted two classes with little diagnostic comorbidity (i.e. 0 diagnoses and 1-2 diagnoses) and found only one class (i.e. 0, 1 or 2 diagnoses; no diagnostic comorbidity class), which was also the largest of the four classes. Furthermore, two other classes of moderate severity emerged (i.e. depression and dissociation). Finally, as expected, we found a most severe class in terms of diagnostic comorbidity named "complex trauma".

In the "no diagnostic comorbidity" class (65.3\%), which was the largest class, more than half of abused youth had not received medical services or been hospitalized for mental health problems, while the rest had at least one diagnosis in a single diagnostic category. It was the only class comprised of participants without diagnoses. This is similar to classes identified in previous person-centered study investigating community-based samples of traumaexposed youth (53-58\%, Ayer et al., 2011; Gallitto et al., 2017) and congruent with current literature on resilience following trauma and CSA among welfare involved youth (Collin-Vézina et al., 2011). Indeed, although CSA's potential to have a devastating impact on psychological health has repeatedly been demonstrated, a growing field of research also reveals that some individuals showing little negative outcomes or even positive outcomes following trauma may be considered resilient (Marriott et al., 2014). Studies have generally reported around a third of sexually abused youth to be asymptomatic (Collin-Vézina et al., 2011; Daigneault et al., 2007; Hébert et al., 2006). Perhaps the higher percentages of these resilient youth in the current study can be explained by our use of administrative data, which can underestimate the rate of disorders for which participants have not consulted a physician (Leach et al., 2015).

In "complex trauma", or the highest diagnostic comorbidity class, all participants presented at least one diagnosis in at least five different categories and had received medical services or been hospitalized for at least one 
diagnosis in the conduct or social disorder category. Oppositional defiant disorder (ODD) and reactive attachment disorder of childhood were among those found in this category and have previously been found to be comorbid to PTSD following CSA (Ackerman et al., 1998; Brosbe, 2014). Furthermore, with more than half of the participants presenting diagnoses from the disorder categories of personality, depression, PTSD, unspecified, anxiety and phobias, somatoform and dissociation, as well as disorders with a physiological impact, links can be made with the concept of CPTSD (Ford, 2011; Ford \& Courtois, 2014; Hyland, Shevlin, Elklit, et al., 2016). Indeed, the impact that trauma, like CSA, can have on systems of self-organization, specifically problems in affective, self-concept, and relational domains (Cloitre et al., 2013) varies between individuals and is heterogeneous. The affective domain problems that are characterized by emotion dysregulation (e.g., heightened emotional reactivity, violent outbursts, reckless or self-destructive behavior, dissociation under stress) are difficulties also found in diagnostic categories of personality, conduct and social, as well as somatoform and dissociation disorders (WHO, 2008). Self-disturbances are characterized by a negative self-concept whereby beliefs of worthlessness are persistent (Cloitre et al., 2013). These difficulties can also be found in categories such as depressive and personality disorders. Interpersonal disturbances are defined by persistent difficulties in sustaining relationships (Cloitre et al., 2013) and can be observed mainly in personality disorders, as well as conduct and social disorders. Furthermore, it is a fair assumption that youth with great comorbidity of mental health disorders might present such distress that it diminishes the quality of social relationships.

Participants in the complex trauma class also reported the highest levels of cumulative maltreatment compared to other classes. These results are coherent with our expectations, as it has previously been reported that a dose-response effect can be observed between cumulative maltreatment types and psychological consequences (Finkelhor et al., 2009). A recent study profiling boys has found similar results: males with most severe CSA profiles tended to report more emotional and physical abuse than males with less severe CSA profiles, and tended to present internalizing, externalizing and trauma symptoms in a dose-response manner pertaining to commutative maltreatment (Lyons, 2018). Results are, furthermore, indicative of what is defined as CPTSD (Cloitre et al., 2013; Hyland, Shevlin, Elklit, et al., 2016), whereby psychological disturbances and perturbed functioning can be observed in a variety of spheres and could be better explained in relation to interpersonal trauma.

Two other classes emerged from analyses, namely the "dissociation" (14\%) and "depression" classes (10\%). This is coherent with previous literature reporting higher rates of dissociative and mood disorders in sexually abused youth (Kisiel et al., 2014). The comorbid diagnoses within these classes were less prevalent than in the "complex trauma" class although more than half of the participants in the "depression" class presented one or two additional diagnoses in distinct categories. Relative to our initial hypotheses, these two classes indicate that there are more diagnostic comorbidity profiles (with two or three diagnoses) than expected, and that these distinct profiles are moderate in severity.

The study documented both male and female victims, although no gender differences were revealed in analyses except for the depression class. Results showed that females were twice as likely as males to belong to the depression class of comorbidity. Indeed, the percentage of males was the lowest in this class (15\%) and underrepresented relative to their proportion in the abused group as a whole (25\%). Although previous studies have found gender differences in the type of symptoms observed in abused children and adolescents (Collin-Vézina et al., 2011; Daigneault, Vézina-Gagnon, et al., 2017; Spataro et al., 2004), and specifically regarding PTSD in adults (Marx \& Sloan, 2003), none has studied gender differences regarding diagnostic comorbidity. Results suggested that although boys were slightly younger than girls when the CSA report was substantiated, and although previous results have shown they tended to receive more medical services than girls for psychological disturbances five years after the substantiated CSA (Daigneault, et al., 2017), boys in the current study didn't present more comorbid diagnoses than girls. Such results are surprising considering participants in the "highly comorbid" class all presented at least one diagnosis in the conduct disorder category, and considering findings from previous research showing that sexually abused boys tend to present more externalizing problems than girls (Spataro et al., 2004; Tyler, 2002), specifically conduct disorders (Daigneault et al., 2017). The contrast with our previous results using this dataset might be explained by the fact that the current study considered diagnostic comorbidity, that is having at least one diagnosis in two distinct categories, and not frequency of mental health consultations and hospitalizations, as previously done. Perhaps boys consult more frequently, for more severe behavioural manifestations, but these manifestations tend to fall in the same large diagnostic category, thus weren't indicative of greater diagnostic comorbidity. Furthermore, the current study included 13 years of data, and not only five as previous studies have done, and this might have an effect on results. 
The number of years following reported CSA was found to be a good predictor of class membership for the complex trauma and dissociation classes. This suggests that because these abused youth were also the ones exposed to the most cumulative maltreatment compared with other classes, we might be able to better understand the symptom profile of each youth when looking at the interpersonal trauma history and trajectory. The high number of comorbid disorders found in this study, as well as the heterogeneity within sexually abused youth, underlines the importance of considering the effects of trauma transdiagnostically, not only in the context of CSA.

\section{Study strengths and limitations}

This study is unique in demonstrating the longitudinal impact of substantiated CSA on mental health and comorbidity profiles in childhood, adolescence and early adulthood. The added value of this study was to show the impact of CSA prospectively, using a general population cohort matched on age, gender, regions and socio-economic levels, while controlling for mental health problems prior to the CSA report being substantiated to CPA, intellectual disability and social and material deprivation. Still, some limitations should be considered. First, we could only consider diagnostic comorbidity for a limited number of categories (i.e., fourteen). A category was comprised of a variety of diagnoses, and if a participant was given different diagnoses that fell within that same category, they were considered only as one diagnostic category. Further studies could include more distinct categories and consider the frequency of each diagnosis in analyses. Second, underrepresentation of the prevalence of mental health diagnoses is possible because only public medical data were used. As such, this dataset lacked data from the private sector, as well as from psychological consultations in all types of settings (i.e. public, schools, private sector). Furthermore, in some cases, patients might not have seen a medical doctor even if they were presenting symptoms. Third, because only one diagnosis can be entered in the system for each visit, it is possible that some disorders might have been incorrectly or partially entered. Indeed, if patients reported an array of various symptoms, doctors might have selected the best fitting diagnosis or the more prominent one. Fourth, and importantly, because CSA is widely underreported (Stoltenborgh et al., 2011), it cannot be assumed that all children in the general population had not been sexually abused. Indeed, they might have been exposed to CSA but not reported it to authorities - they might have reported it to another CPA than the one included in the study if they moved to another CPA sector during the study, or they might have reported CSA to the participating CPA outside of data collection years. All these limits might underestimate the prevalence of diagnoses and diagnostic comorbidity, as well as the differences between the groups, and thus limits the generalization of results to CPA involved youth.

\section{Directions for future research and clinical implications}

The current study's results add to past research in showing CSA's potential impact on the psychological wellbeing of children and adolescents, as well as on public health care systems. Early psychological assessments following substantiated reports of CSA, as well as all other types of maltreatment, are warranted to provide appropriate and immediate care. Moreover, half of the children and adolescents exposed to CSA in this study presented little or no mental health diagnoses according to the available medical data, indicating a potentially resilient functioning. These results should, however, not impede efforts to alternatively support and monitor youth who have been exposed to interpersonal trauma like CSA and maltreatment. They may have been underdiagnosed or not consulted for mental health problems even if they were suffering from important symptoms or disorders. Current findings reiterate the importance of tailoring interventions to the specific needs and clinical profiles of each abused child and adolescent, namely focusing on inner strengths and interpersonal features (i.e. adaptive coping strategies, attributional style, and self-esteem) as has been stated in past research (Marriott et al., 2014). Indeed, continued monitoring could be necessary, as symptoms can sometimes be latent and present themselves in later circumstances. Results also suggest two subgroups presenting some diagnostic comorbidity and one subgroup presenting very high diagnostic comorbidity, highlighting how symptoms following CSA and maltreatment can greatly vary, and necessitate individualized treatment. For the youth presenting such high diagnostic comorbidity, trauma-focused interventions could be warranted in order to address PTSD symptoms and behaviour problems, exhibit more positive functioning and improve strengths (Bartlett et al., 2018). Programs like trauma-focused CBT (TF-CBT; Cohen et al., 2012) and attachment, regulation and competency (ARC; Blaustein \& Kinniburgh, 2010; Kinniburgh et al., 2005) are promising avenues to treat complex trauma and could be considered in the case of exposure to CSA and maltreatment. Current findings contribute to data for the inclusion of a complex PTSD diagnosis in the revised version of the fifth edition of the DSM (APA, 2013), as is the case in the 11th ICD version (WHO, 2020). 
Sexually abused youth's varied profiles warrant varied interventions. Specifically, integrated trauma informed interventions are needed to address the impact of cumulative maltreatment experiences and the psychiatric comorbidity some youth exhibit over longer periods of time. Such information is important for evaluation and treatment planning, and specifically for medical diagnostic training. Indeed, some youth accumulating various diagnoses may benefit from a unified diagnosis of complex trauma, which is uncommonly used in Canada. Future studies could further investigate the developmental trajectories of youth presenting highly comorbid profiles and do so using national samples so that results may be generalized beyond youth under CPA care.

\section{Funding}

Authors thank the Fonds d'aide aux victimes d'actes criminels (FAVAC) from the Ministry of Justice, the Centre de recherche interdisciplinaire sur les problèmes conjugaux et les agressions sexuelles (CRIPCAS) and the Équipe violence sexuelle et santé (ÉVISSA) for financial support. The opinions expressed in the article are those of the authors and do not necessarily reflect those of the Ministry of Justice of Québec.

\section{Conflict of interest}

The authors have no conflict of interest to disclose.

\section{References}

Ackerman, P. T., Newton, J. E., McPherson, W., Jones, J. G., \& Dykman, R. A. (1998). Prevalence of post traumatic stress disorder and other psychiatric diagnoses in three groups of abused children (sexual, physical, and both). Child Abuse \& Neglect, 22(8), 759774. https://doi.org/10.1016/S0145-2134(98)00062-3

Afifi, T. O., MacMillan, H. L., Taillieu, T., Cheung, K., Turner, S., Tonmyr, L., \& Hovdestad, W. (2015). Relationship between child abuse exposure and reported contact with child protection organizations: Results from the Canadian Community Health Survey. Child Abuse \& Neglect, 46, 198-206. https://doi.org/10.1016/j.chiabu.2015.05.001

American Psychiatric Association. (2013). Diagnostic and Statistical Manual of Mental Disorders (5th ed.). American Psychiatric Association. https://doi.org/10.1176/appi.books.9780890425596

Ayer, L., Danielson, C. K., Amstadter, A. B., Ruggiero, K., Saunders, B., \& Kilpatrick, D. (2011). Latent classes of adolescent posttraumatic stress disorder predict functioning and disorder after 1 year. Journal of the American Academy of Child \& Adolescent Psychiatry, 504), 364-375. https://doi.org/10.1016/j.jaac.2011.01.004

Bartlett, J. D., Griffin, J. L., Spinazzola, J., Fraser, J. G., Noroña, C. R., Bodian, R., Todd, M., Montagna, C., \& Barto, B. (2018). The impact of a statewide trauma-informed care initiative in child welfare on the well-being of children and youth with complex trauma. Children and Youth Services Review, 84,110-117. https://doi.org/10.1016/j.childyouth.2017.11.015

Belsky, J. (1993). Etiology of child maltreatment: A developmental-ecological analysis. Psychological Bulletin, 114(3), $413-434$. https://doi.org/10.1037/0033-2909.114.3.413

Blaustein, M. E., \& Kinniburgh, K. M. (2010). Treating traumatic stress in children and adolescents: How to foster resilience through attachment, self-regulation, and competency. Guilford Press.

Bourgeois, C., Lecomte, T., \& Daigneault, I. (2018). Psychotic disorders in sexually abused youth: A prospective matched-cohort study. Schizophrenia Research. 199, 123-127. https://doi.org/10.1016/j.schres.2018.03.020

Brady, K. L., \& Caraway, S. J. (2002). Home away from home: factors associated with current functioning in children living in a residential treatment setting. Child Abuse \& Neglect, 26(11), 1149-1163. https://doi.org/10.1016/S0145-2134(02)00389-7

Brand, E. F., King, C. A., Olson, E., Ghaziuddin, N., \& Naylor, M. (1996). Depressed adolescents with a history of sexual abuse: Diagnostic comorbidity and suicidality. Journal of the American Academy of Child \& Adolescent Psychiatry, 35(1), 34-41. https://doi.org/10.1097/00004583-199601000-00010

Brewin, C. R., Andrews, B., \& Gotlib, I. H. (1993). Psychopathology and early experience: A reappraisal of retrospective reports. Psychological Bulletin, 113(1), 82-98. https://doi.org/10.1037/0033-2909.113.1.82

Brodbeck, J., Fassbinder, E., Schweiger, U., Fehr, A., Späth, C., \& Klein, J. P. (2018). Differential associations between patterns of child maltreatment and comorbidity in adult depressed patients. Journal of Affective Disorders. 230, 34-41. https://doi.org/10.1016/j.jad.2017.12.077

Brosbe, M. S. (2013). Beyond PTSD: Predictors of psychological comorbidities in sexually abused children (Publication No. 3591524) [Doctoral dissertation, Nova Southeastern University.] ProQuest Dissertations \& Theses Global. (1434876300). 
Brown, S. M., Rienks, S., McCrae, J. S., \& Watamura, S. E. (2019). The co-occurrence of adverse childhood experiences among children investigated for child maltreatment: A latent class analysis. Child Abuse \& Neglect, 87, 18-27 https://doi.org/10.1016/j.chiabu.2017.11.010

Brownell, M. D., \& Jutte, D. P. (2013). Administrative data linkage as a tool for child maltreatment research. Child Abuse \& Neglect, 37(2-3), 120-124. https://doi.org/10.1016/j.chiabu.2012.09.013

Choi, K. R., Seng, J. S., Briggs, E. C., Munro-Kramer, M. L., Graham-Bermann, S. A., Lee, R. C., \& Ford, J. D. (2017). The dissociative subtype of Posttraumatic Stress Disorder (PTSD) among adolescents: Co-occurring PTSD, depersonalization/ derealization, and other dissociation symptoms. Journal of the American Academy of Child \& Adolescent Psychiatry, 56(12), $1062-1072$. https://doi.org/10.1016/j.jaac.2017.09.425

Cloitre, M., Garvert, D. W., Brewin, C. R., Bryant, R. A., \& Maercker, A. (2013). Evidence for proposed ICD-11 PTSD and complex PTSD: A latent profile analysis. European Journal of Psychotraumatology, 4(1), Article 20706. https://doi.org/10.3402/ejpt.v4i0.20706

Cloitre, M., Stolbach, B. C., Herman, J. L., van der Kolk, B., Pynoos, R., Wang, J., \& Petkova, E. (2009). A developmental approach to complex PTSD: Childhood and adult cumulative trauma as predictors of symptom complexity. Journal of Traumatic Stress, 22(5), 399-408. https://doi.org/10.1002/jts.20444

Cohen, J. A., Mannarino, A. P., Kliethermes, M., \& Murray, L. A. (2012). Trauma-focused CBT for youth with complex trauma. Child Abuse \& Neglect, 36(6), 528-541. https://doi.org/10.1016/j.chiabu.2012.03.007

Collin-Vézina, D., Coleman, K., Milne, L., Sell, J., \& Daigneault, I. (2011). Trauma experiences, maltreatment-related impairments, and resilience among child welfare youth in residential care. International Journal of Mental Health and Addiction, 9(5), 577-589. https://doi.org/10.1007/s11469-011-9323-8

Collins, L. M., \& Lanza, S. T. (2010). Latent class and latent transition analysis: With applications in the social, behavioral, and health sciences. Wiley.

Connor, D. F., Doerfler, L. A., Toscano, P. F., Volungis, A. M., \& Steingard, R. J. (2004). Characteristics of children and adolescents admitted to a residential treatment center. Journal of Child and Family Studies, 13(4), $497-510$. https://doi.org/10.1023/B:JCFS.0000044730.66750.57

Cook, A., Spinazzola, J., Ford, J. D., Lanktree, C., Blaustein, M., Cloitre, M., DeRosa, R., Hubbard, R., Kagan, R., Liautaud, J., Mallah, K., Olafson, E., \& van der Kolk, B. A. (2005). Complex trauma in children and adolescents. Psychiatric Annals, 35(5), $390-398$.

Cyr, K., Chamberland, C., Clément, M.-È., Lessard, G., Wemmers, J.-A., Collin-Vézina, D., Gagné, M.-H., \& Damant, D. (2013). Polyvictimization and victimization of children and youth: Results from a populational survey. Child Abuse \& Neglect, 3710), 814-820. http://doi.org/10.1016/j.chiabu.2013.03.009

D'Andrea, W., Ford, J., Stolbach, B., Spinazzola, J., \& Van der Kolk, B. A. (2012). Understanding interpersonal trauma in children: why we need a developmentally appropriate trauma diagnosis. American Journal of Orthopsychiatry, 82(2), $187-200$. https://doi.org/10.1111/j.1939-0025.2012.01154.x

Daigneault, I., Bourgeois, C., Vézina-Gagnon, P., Alie-Poirier, A., Dargan, S., Hébert, M., \& Frappier, J.-Y. (2017). Physical and mental health of sexually abused boys: A 5 year matched-control and cohort study. Journal of Child \& Adolescent Trauma, 10(1), 9-17. https://doi.org/10.1007/s40653-016-0120-1

Daigneault, l., Cyr, M., \& Tourigny, M. (2003). Profil psychologique d'adolescentes agressées sexuellement et prises en charge par les services de protection de la jeunesse. Santé Mentale au Québec, 28(2), 211-232. https://doi.org/10.7202/008625ar

Daigneault, I., Hébert, M., \& Tourigny, M. (2007). Personal and interpersonal characteristics related to resilient developmental pathways of sexually abused adolescents. Child and Adolescent Psychiatric Clinics of North America, 16(2), 415-434. https://doi.org/10.1016/j.chc.2006.11.002

Daigneault, l., Tourigny, M., \& Cyr, M. (2004). Description of trauma and resilience in sexually abused adolescents: An integrated assessment. Journal of Trauma Practice, 3(2), 23-47. https://doi.org/10.1300/J189v03n02_02

Daigneault, I., Vézina-Gagnon, P., Bourgeois, C., Esposito, T., \& Hébert, M. (2017). Physical and mental health of children with substantiated sexual abuse: Gender comparisons from a matched-control cohort study. Child Abuse \& Neglect, 66, $155-165$. https://doi.org/10.1016/j.chiabu.2017.02.038

Euser, S., Alink, L. R. A., Tharner, A., IJzendoorn, M. H., \& Bakermans-Kranenburg, M. J. (2015). The prevalence of child sexual abuse in out-of-home care: Increased risk for children with a mild intellectual disability. Journal of Applied Research in Intellectual Disabilities, 29(1), 83-92. https://doi.org/10.1111/jar.12160

Felitti, V. J., Anda, R. F., Nordenberg, D., Williamson, D. F., Spitz, A. M., Edwards, V., Koss, M. P., \& Marks, J. S. (1998). Relationship of childhood abuse and household dysfunction to many of the leading causes of death in adults - The adverse childhood experiences (ACE) study. American Journal of Preventive Medicine, 14(4), 245-258. https://doi.org/10.1016/s07493797(98)00017-8 
Fergusson, D. M., Boden, J. M., \& Horwood, L. (2008). Exposure to childhood sexual and physical abuse and adjustment in early adulthood. Child Abuse \& Neglect, 32(6), 607-619. https://doi.org/10.1016/j.chiabu.2006.12.018

Finkelhor, D., \& Hashima, P. Y. (2001). The victimization of children and youth: A comprehensive overview. In S. O. White (ed.), Handbook of Youth and Justice (pp. 49-78). The Plenum Series in Crime and Justice. Springer. https://doi.org/10.1007/978-14615-1289-9_4

Finkelhor, D., Ormrod, R. K., \& Turner, H. A. (2009). Lifetime assessment of poly-victimization in a national sample of children and youth. Child Abuse \& Neglect, 33(7), 403-411. https://doi.org/10.1016/j.chiabu.2008.09.012

Finkelhor, D., Shattuck, A., Turner, H., \& Hamby, S. (2015). A revised inventory of adverse childhood experiences. Child Abuse \& Neglect, 48, 13-21. https://doi.org/10.1016/j.chiabu.2015.07.011

Ford, J. D. (2011). Future directions in conceptualizing complex posttraumatic stress syndromes in childhood and adolescence: Toward a developmental trauma diagnosis. In V. Ardino (Ed.), Post-traumatic syndromes in childhood and adolescence: $A$ handbook of research and practice (pp. 433-448). Wiley Blackwell. https://doi.org/10.1002/9780470669280.ch22

Ford, J. D., \& Courtois, C. A. (2014). Complex PTSD, affect dysregulation, and borderline personality disorder. Borderline Personality Disorder and Emotion Dysregulation, 1, Article 9. https://doi.org/10.1186/2051-6673-1-9

Ford, J. D., Elhai, J. D., Connor, D. F., \& Frueh, B. (2010). Poly-victimization and risk of posttraumatic, depressive, and substance use disorders and involvement in delinquency in a national sample of adolescents. Journal of Adolescent Health, 46(6), 545-552. https://doi.org/10.1016/j.jadohealth.2009.11.212

Ford, J. D., Gagnon, K., Connor, D. F., \& Pearson, G. (2011). History of interpersonal violence, abuse, and nonvictimization trauma and severity of psychiatric symptoms among children in outpatient psychiatric treatment. Journal of Interpersona/ Violence, 26(16), 3316-3337. https://doi.org/10.1177/0886260510393009

Gallitto, E., Lyons, J., Weegar, K., Romano, E., \& Team, M. A. P. R. (2017). Trauma-symptom profiles of adolescents in child welfare. Child Abuse \& Neglect, 68, 25-35. https://doi.org/10.1016/j.chiabu.2017.03.011

Goldman, J. D. G., \& Padayachi, U. K. (2000). Some methodological problems in estimating incidence and prevalence in child sexual abuse research. Journal of Sex Research, 374), 305-314. https://doi.org/10.1080/00224490009552052

Gouvernement du Québec. (2008). Faire un signalement au DPJ, c'est déjà protéger un enfant. Direction des communications du Ministère de la Santé et des Services sociaux du Québec. https://publications.msss.gouv.qc.ca/msss/document-000895/

Gouvernement du Québec. (2016). Filing a report to the DYP is already protecting a child: When and how to file a report? La Direction des communications du ministère de la Santé et des Services sociaux du Québec. https://publications.msss.gouv.qc.ca/msss/en/document-000897/

Hébert, M., Parent, N., Daignault, I. V., \& Tourigny, M. (2006). A typological analysis of behavioral profiles of sexually abused children. Child Maltreatment, 11(3), 203-216. https://doi.org/10.1177/1077559506287866

Hillberg, T., Hamilton-Giachritsis, C., \& Dixon, L. (2011). Review of meta-analyses on the association between child sexual abuse and adult mental health difficulties: A systematic approach. Trauma, Violence, \& Abuse, 12(1), 38-49. https://doi.org/10.1177/1524838010386812

Hyland, P., Shevlin, M., Elklit, A., Murphy, J., Vallieres, F., Garvert, D. W., \& Cloitre, M. (2016). An assessment of the construct validity of the ICD-11 proposal for complex posttraumatic stress disorder. Psychological Trauma: Theory, Research, Practice, and Policy, 91), 1-9. https://doi.org/10.1037/tra0000114

Hyland, P., Shevlin, M., McNally, S., Murphy, J., Hansen, M., \& Elklit, A. (2016). Exploring differences between the ICD-11 and DSM-5 models of PTSD: Does it matter which model is used? Journal of Anxiety Disorders, 37, 48-53. https://doi.org/10.1016/j.janxdis.2015.11.002

Johnson, R. J. (2008). Advances in understanding and treating childhood sexual abuse: Implications for research and policy. Family \& Community Health, 31, S24-S31. https://doi.org/10.1097/01.FCH.0000304015.67513.ea

Kaplow, J. B., Hall, E., Koenen, K. C., Dodge, K. A., \& Amaya-Jackson, L. (2008). Dissociation predicts later attention problems in sexually abused children. Child Abuse \& Neglect, 32(2), 261-275. https://doi.org/10.1016/j.chiabu.2007.07.005

Kearney, C. A., Wechsler, A., Kaur, H., \& Lemos-Miller, A. (2010). Posttraumatic stress disorder in maltreated youth: A review of contemporary research and thought. Clinical Child and Family Psychology Review, 13(1), 46-76. https://doi.org/10.1007/s10567-009-0061-4

Kendall-Tackett, K. A., Williams, L. M., \& Finkelhor, D. (1993). Impact of sexual abuse on children: A review and synthesis of recent empirical studies. Psychological Bulletin, 113(1), 164-180. https://doi.org/10.1037/0033-2909.113.1.164

Kessler, R. C., McLaughlin, K. A., Green, J. G., Gruber, M. J., Sampson, N. A., Zaslavsky, A. M., Aguilar-Gaxiola, S., Alhamzawi, A. O., Alonso, A., Angermeyer, M., Benjet, C., Bromet, E., Chatterji, S., De Girolamo, G., Demyttenaere, K., Fayyad, J., Florescu, S., Gal, G., Gureje, O., ... Williams, D. R. (2010). Childhood adversities and adult psychopathology in the WHO World Mental Health Surveys. The British Journal of Psychiatry, 1975), 378-385. http://doi.org/10.1192/bjp.bp.110.080499 
Kilpatrick, D. G., Ruggiero, K. J., Acierno, R., Saunders, B. E., Resnick, H. S., \& Best, C. L. (2003). Violence and risk of PTSD, major depression, substance abuse/dependence, and comorbidity: Results from the National Survey of Adolescents. Journal of Consulting and Clinical Psychology, 71(4), 692-700. https://doi.org/10.1037/0022-006X.71.4.692

Kinniburgh, K. J., Blaustein, M., Spinazzola, J., \& van der Kolk, B. A. (2005). Attachment, self-regulation, and competency: A comprehensive intervention framework for children with complex trauma. Psychiatric Annals, 35(5), 424-430. https://doi.org/10.3928/00485713-20050501-08

Kisiel, C. L., Fehrenbach, T., Torgersen, E., Stolbach, B., McClelland, G., Griffin, G., \& Burkman, K. (2014). Constellations of interpersonal trauma and symptoms in child welfare: Implications for a developmental trauma framework. Journal of Family Violence, 29(1), 1-14. https://doi.org/10.1007/s10896-013-9559-0

Lau, A. S., Leeb, R. T., English, D., Graham, J. C., Briggs, E. C., Brody, K. E., \& Marshall, J. M. (2005). What's in a name? A comparison of methods for classifying predominant type of maltreatment. Child Abuse \& Neglect, 29(5), 533-551. https://doi.org/10.1016/j.chiabu.2003.05.005

Leach, C., Baksheev, G. N., \& Powell, M. (2015). Child sexual abuse research: Challenges of case tracking through administrative databases. Psychiatry, Psychology and Law, 22(6), 912-919. https://doi.org/10.1080/13218719.2015.1019333

Lyons, J. (2018). Sexual abuse characteristics and psychological functioning among male survivors of childhood sexual abuse. [Doctoral dissertation]. University of Ottawa. http://doi.org/10.20381/ruor-21853

Maniglio, R. (2009). The impact of child sexual abuse on health: A systematic review of reviews. Clinical Psychology Review, 297), 647-657. https://doi.org/10.1016/j.cpr.2009.08.003

Marriott, C., Hamilton-Giachritsis, C., \& Harrop, C. (2014). Factors promoting resilience following childhood sexual abuse: A structured, narrative review of the literature. Child Abuse Review, 23(1), 17-34. https://doi.org/10.1002/car.2258

Martin, G., Bergen, H. A., Richardson, A. S., Roeger, L., \& Allison, S. (2004). Sexual abuse and suicidality: gender differences in a large community sample of adolescents. Child Abuse \& Neglect, 28(5), 491-503. https://doi.org/10.1016/j.chiabu.2003.08.006

Marx, B. P., \& Sloan, D. M. (2003). The effects of trauma history, gender, and race on alcohol use and posttraumatic stress symptoms in a college student sample. Addictive Behaviors, 28(9), 1631-1647. https://doi.org/10.1016/j.addbeh.2003.08.039

Mathews, B., \& Collin-Vézina, D. (2019). Child sexual abuse: Toward a conceptual model and definition. Trauma, Violence, \& Abuse, 20(2), 131-148. https://doi.org/10.1177/1524838017738726

McLeer, S. V., Dixon, F. J., Henry, D., Ruggiero, K., Escovitz, K., Niedda, T., \& Scholle, R. (1998). Psychopathology in non-clinically referred sexually abused children. Journal of the American Academy of Child \& Adolescent Psychiatry, 37(12), 1326-1333. https://doi.org/10.1097/00004583-199812000-00017

Naar-King, S., Silvern, L., Ryan, V., \& Sebring, D. (2002). Type and severity of abuse as predictors of psychiatric symptoms in adolescence. Journal of Family Violence, 172), 133-149. https://doi.org/10.1023/A:1015057416979

Niven, D. J., Berthiaume, L. R., Fick, G. H., \& Laupland, K. B. (2012). Matched case-control studies: A review of reported statistical methodology. Clinical Epidemiology, 4(1), 99-110. https://doi.org/10.2147/CLEP.S30816

Nylund, K. L., Asparouhov, T., \& Muthén, B. O. (2007). Deciding on the number of classes in latent class analysis and growth mixture modeling: A Monte Carlo simulation study. Structural Equation Modeling, 14(4), $535-569$. https://doi.org/10.1080/10705510701575396

O'Donnell, M., Nassar, N., Leonard, H., Jacoby, P., Mathews, R., Patterson, Y., \& Stanley, F. (2010a). Characteristics of non-Aboriginal and Aboriginal children and families with substantiated child maltreatment: A population-based study. International Journal of Epidemiology, 39(3), 921-928. https://doi.org/10.1093/ije/dyq005

O'Donnell, M., Nassar, N., Leonard, H., Jacoby, P., Mathews, R., Patterson, Y., \& Stanley, F. (2010b). Rates and types of hospitalisations for children who have subsequent contact with the child protection system: a population based case-control study. Journal of Epidemiology and Community Health, 64, 784-788. https://doi.org/10.1136/jech.2009.093393

Oquendo, M. A., Friend, J. M., Halberstam, B., Brodsky, B. S., Burke, A. K., Grunebaum, M. F., Malone, K. M., \& Mann, J. J. (2003). Association of comorbid posttraumatic stress disorder and major depression with greater risk for suicidal behavior. American Journal of Psychiatry, 160(3), 580-582. https://doi.org/10.1176/appi.ajp.160.3.580

Pampalon, R., Hamel, D., \& Gamache, P. (2010). Indice de défavorisation matérielle et sociale du Québec: suivi méthodologique de 1991 à 2006. Institut national de santé publique du Québec. http://www.inspq.qc.ca/pdf/publications/1176_IndiceDefavorisation1991A2006.pdf.

Pauzé, R., Toupin, J., Déry, M., Mercier, H., Cyr, M., Cyr, F., \& Frappier, J.-Y. (2000). Les soins aux jeunes en difficulté - QC-411 - Volet 1. Portrait des jeunes inscrits à la prise en charge des centres jeunesse du Québec et description des services reçus au cours des premiers mois. Groupe de recherche sur les inadaptations sociales de l'enfance [GRISE], Université de Sherbrooke.

Putnam, F. W. (2003). Ten-year research update review: Child sexual abuse. Journal of the American Academy of Child \& Adolescent Psychiatry, 42(3), 269-278. https://doi.org/10.1097/00004583-200303000-00006 
R Core Team (2017). R: A language and environment for statistical computing. R Foundation for Statistical Computing. http://www. Rproject.org/

Rivera, P. M., Fincham, F. D., \& Bray, B. C. (2018). Latent classes of maltreatment: A systematic review and critique. Child Maltreatment, 23(1), 3-24. https://doi.org/10.1177/1077559517728125

Shin, S. H., Hong, H. G., \& Hazen, A. L. (2010). Childhood sexual abuse and adolescent substance use: A latent class analysis. Drug \& Alcohol Dependence, 109(1-3), 226-235. https://doi.org/10.1016/j.drugalcdep.2010.01.013

Silverman, A. B., Reinherz, H. Z., \& Giaconia, R. M. (1996). The long-term sequelae of child and adolescent abuse: A longitudinal community study. Child Abuse \& Neglect, 208), 709-723. https://doi.org/10.1016/0145-2134(96)00059-2

Spataro, J., Mullen, P. E., Burgess, P. M., Wells, D. L., \& Moss, S. A. (2004). Impact of child sexual abuse on mental health: Prospective study in males and females. The British Journal of Psychiatry, 184(5), 416-421. https://doi.org/10.1192/bjp.184.5.416

Stanley, F. (2003). Record linkage-public good or invasion of privacy. In Proceedings of the 25th international conference of data protection and privacy commissioners (pp. 10-12).

Steine, I. M., Winje, D., Krystal, J. H., Bjorvatn, B., Milde, A. M., Grønli, J., Nordhus, I. H., \& Pallesen, S. (2017). Cumulative childhood maltreatment and its dose-response relation with adult symptomatology: findings in a sample of adult survivors of sexual abuse. Child Abuse \& Neglect, 65, 99-111. https://doi.org/10.1016/j.chiabu.2017.01.008

Stoltenborgh, M., van ljzendoorn, M. H., Euser, E. M., \& Bakermans-Kranenburg, M. J. (2011). A global perspective on child sexual abuse: Meta-analysis of prevalence around the world. Child Maltreatment, 16(2), 79-101. https://doi.org/10.1177/1077559511403920

Straus, M. A. (1998). Identification of child maltreatment with the Parent-Child Conflict Tactics Scales: Development and psychometric data for a national sample of American parents. Child Abuse \& Neglect, 22(4), $249-265$. https://doi.org/10.1016/S0145-2134(97)00174-9

Tanaka, M., Wekerle, C., Schmuck, M. L., \& Paglia-Boak, A. (2011). The linkages among childhood maltreatment, adolescent mental health, and self-compassion in child welfare adolescents. Child Abuse and Neglect, 35(10), 887-898. https://doi.org/10.1016/j.chiabu.2011.07.003

Tourigny, M., Hébert, M., Joly, J., Cyr, M., \& Baril, K. (2008). Prevalence and co-occurrence of violence against children in the Quebec population. Australian and New Zealand Journal of Public Health, 32(4), 331-335. https://doi.org/10.1111/j.17536405.2008.00250.x

Tremblay, C., Hébert, M., \& Piché, C. (2000). Type I and type II posttraumatic stress disorder in sexually abused children. Journal of Child Sexual Abuse, 9(1),65-90. https://doi.org/10.1300/J070v09n01_05

Turner, H. A., Finkelhor, D., \& Ormrod, R. (2010). Poly-victimization in a national sample of children and youth. American Journal of Preventive Medicine, 38(3), 323-330. https://doi.org/10.1016/j.amepre.2009.11.012

Tyler, K. A. (2002). Social and emotional outcomes of childhood sexual abuse: A review of recent research. Aggression and Violent Behavior, 76), 567-589. https://doi.org/10.1016/S1359-1789(01)00047-7

Vachon, D. D., Krueger, R. F., Rogosch, F. A., \& Cicchetti, D. (2015). Assessment of the harmful psychiatric and behavioral effects of different forms of child maltreatment. JAMA Psychiatry, 72(11), 1135-1142. https://doi.org/10.1001/jamapsychiatry.2015.1792

van der Kolk, B. A. (2017). Developmental trauma disorder: Toward a rational diagnosis for children with complex trauma histories. Psychiatric Annals, 35(5), 401-408. https://doi.org/10.3928/00485713-20050501-06

Wekerle, C., Goldstein, A. L., Tanaka, M., \& Tonmyr, L. (2017). Childhood sexual abuse, sexual motives, and adolescent sexual risk-taking among males and females receiving child welfare services. Child Abuse \& Neglect, 66, 101-111. https://doi.org/10.1016/j.chiabu.2017.01.013

World Health Organization. (2008). The ICD-10 classification of mental and behavioral disorders: diagnostic criteria for research. https://www.who.int/classifications/icd/en/GRNBOOK.pdf?ua=1

World Health Organization (2020). International statistical classification of diseases and related health problems (1 th $^{\text {ed.). }}$. https://icd.who.int/ 